\title{
Empirical Study on Returns, Volatility and Investor Sentiment of the Growth Enterprise Market in China
}

\author{
WeiLi Xia ${ }^{1, a}$ and LinLin Guo ${ }^{2, b}$ \\ ${ }^{1}$ School of Northwestern Polytechnical University, Xi'an 710129, China; \\ ${ }^{2}$ School of Northwestern Polytechnical University, Xi'an 710129, China. \\ a xiaweili@nwpu.edu.cn, ${ }^{\mathrm{b}}$ kelin7777@126.com
}

Keywords: Investor Sentiment, GEM, Market Fluctuations.

\begin{abstract}
Since the establishment of the Growth Enterprise Market (GEM), the non-rationality of stock value appraisal system is prominent, while the swings in sentiment of investors in GEM significantly affect the transactions of assets and price determination. The result shows that there is no long-term correlation between the sentiment of investors in GEM and stock returns. Past market returns would observably affect investor sentiment in the short term, but investor sentiment would not affect short-term stock returns; investor sentiment would affect the level of market fluctuations, but market fluctuations would not observably affect investor sentiment.
\end{abstract}

\section{Introduction}

Since the establishment of GEM more than five years ago, the phenomena of "three highs (high price earnings ratio, high valuations and high volatility)” have always been extremely prominent. No matter horizontally compared with other sections or vertically compared with histories, the price earnings ratio and the overall valuations of GEM are the highest, with relatively sharp market fluctuations. This article holds the opinion that, under the condition of stable macroeconomic fundamentals, the occurrence of such financial phenomena is more likely to be caused by the irrational behaviors and the sharp swing in sentiment of investors. Meanwhile, as the industry has not arrived at a clear consensus on the valuations of stocks listed on GEM at present, investor sentiment may easily encounter the problems of extreme optimism and extreme pessimism, which would result in the increase of overall swings in financial activities in GEM. Therefore, from the perspective of behavioral finance, this article probes into the relations between investor sentiment in GEM and stock returns and market fluctuations and attempts to provide certain enlightenment for regulators to formulate related policies.

\section{Literature Review}

Due to the inherent complexity and dynamic variability of investor sentiment, it is particularly difficult to measure it. Aiming at the researches of this field, domestic and overseas scholars gradually develop two methods to measure investor sentiment, that is, direct sentiment indicator and indirect sentiment indicator. Direct sentiment indicator refers to the indicator constructed by releasing organizations which collect bullish and bearish opinions of different investors on future markets through issuing questionnaires, such as the Bullish Consensus, the Consumer Confidence Index, etc.. Indirect sentiment indicator refers to certain indicator constructed by utilizing transaction data of a single market or multiple markets to indirectly reflect investor sentiment, which can be divided into single indicator and complex index. With the extensive approval of existence of investor sentiment and the affirmation of whether swings in sentiment constitute systematic noise trading risk of assets pricing, scholars turn to research the relations between investor sentiment and stock returns and market fluctuations. There are more researches on relations between investor sentiment and stock returns, the research conducted by Fisher and Statman found that a significant negative correlation existed between strategic and individual investors and market returns in the next period; Brown and Cliff conducted a systematic research on investor sentiment 
and recent market returns and found that historical market returns was an important influence factor of sentiment, and a significant correlation existed between the swings in investor sentiment and stock returns in the same period. However, the conclusion that sentiment would affect future market returns in the short term was not supported.

\section{Measurement of Investor Sentiment Based on China's GEM}

Based on the analysis of theories related to measurement of investor sentiment and combining the analysis with specified situation of China's GEM and the availability of research data, this article adopts principal component analysis to construct complex investor sentiment index of China's GEM. Taking week as the unit, the time span is from October 2009 to May 2015. Lot winning rate (LWR), offline placement ratio (SP), IPO initial returns (IPOR), turnover rate (TURN), rise and down proportions (RADL) and average stock price (ASP) are selected as the indexes of sentiment model. Among them, the data of lot winning rate (LWR) and offline placement ratio (SP) comes from listing announcements of companies listed on GEM. The data of IPO initial returns (IPOR) and turnover rate (TURN) comes from weekly market statistics of GEM released by Shenzhen Stock Exchange, and the data of rise and down proportions (RADL) and average stock price (ASP) comes from Wind Database.

Looking In summary, the measurement of the investor sentiment index is:

$$
I S I_{t}=0.524 L W R_{t}+0.436 S P_{t-1}+0.291 I P O R_{t-1}+0.472 T U R N_{t-1}+0.549 R A D L_{t}+0.347 A P_{t}
$$

\section{Investor Sentiment and Stock Returns}

To study the correlation between investor sentiment and stock returns in the Growth Enterprise Market (GEM), this paper uses the VAR model for analysis and performs Granger causality test.

\section{Unit Root Test.}

First, use the ADF method for unit root test of investor sentiment. The ADF test results in Table 1 show that we fail to reject the null hypotheses at the $25 \%$ significance level, which proves the presence of unit root in investor sentiment, so it is unstable. Under first differencing, the ADF test for investor sentiment is conducted again, and the results in Table 1 show that we reject the null hypothesis, indicating that the unit root does not exist in investor sentiment under first differences, namely ISI $\sim$ I (1).

Second, use the ADF method for unit root test of stock returns in the GEM. From Table 2, the ADF test results show that we reject the null hypothesis, thereby showing there is no unit root in GEM returns, namely RETURN I (0).

Therefore, this paper finds that investor sentiment is I (1), whereas the GEM return is I (0), that is, the two time series are not integrated of the same order, and thus leads to the conclusion that there is no long-standing relationship between investor sentiment and stock return in GEM

Table 1 Investor sentiment ADF test of GEM

\begin{tabular}{|c|c|c|c|c|c|}
\hline & & \multicolumn{2}{|c|}{ Horizontal value } & \multicolumn{2}{|c|}{ first difference } \\
\hline & & t-Statistic & Prob.* & t-Statistic & Prob.* \\
\hline Augmented Dickey- & r test statistic & -2.067163 & 0.2584 & -9.793285 & 0.0000 \\
\hline Test critical values: & $\begin{array}{c}\text { 1\% level } \\
5 \% \text { level } \\
10 \% \text { level }\end{array}$ & $\begin{array}{l}-3.501445 \\
-2.892536 \\
-2.583371\end{array}$ & & $\begin{array}{l}-3.502238 \\
-2.892879 \\
-2.583553\end{array}$ & \\
\hline
\end{tabular}

Table 2 Return ADF test of GEM

\begin{tabular}{cccc}
\hline & t-Statistic & Prob. $^{*}$ \\
\hline \multicolumn{2}{c}{ Augmented Dickey-Fuller test statistic } & -4.967283 & 0.0001 \\
\hline Test critical values: & 1\% level & -3.502238 & \\
& $5 \%$ level & -2.892879 & \\
$10 \%$ level & -2.583553 & \\
\hline
\end{tabular}




\section{VAR Model Analysis.}

However, to explore whether there is short-term dynamic relationship between them, this paper uses the VAR model to study the standard error of coefficient estimates (in parentheses), and t-statistics (in square brackets). The result shows a strong relationship between GEM returns and investor sentiment when there is one-period lagging, and the t-statistic is 4.85995, which is significant. In the GEM, no strong relationship has been found between investor sentiment and the return of two periods in the future. Therefore, it shows that past stock returns significantly affects investor sentiment in the short-term, while the investor sentiment in GEM does not affect future stock returns in the short-term.

\section{Investor Sentiment and Market Volatility}

This paper applies the GARCH $(1,1)$ model for estimating the conditional heteroskedasticity of GEM returns. The conditional heteroskedasticityGARCH01 calculated by EViews is recorded as VOL. The result presents the ADF unit root test results for the VOL sequence, and shows that the market volatility is only integrated under first differencing, i.e., VOL I (1), which is the same for investor sentiment. Subsequently, the Granger causality test is conducted to test the relationship between market volatility and investor sentiment. As shown in Table 3, investor sentiment influences market volatility in the short-term, whereas market volatility does not affect investor sentiment in the short-term. Therefore, this paper accepts Hypothesis 1 and rejects Hypothesis 2. The rising investor sentiment will lead to increased market volatility, whereas the degree of market volatility will not affect the level of investor sentiment.

Table 3 Grainger Granger causality test of Investor sentiment and market volatility

\begin{tabular}{ccccc}
\hline & \multicolumn{2}{c}{ Lag period 2 } & \multicolumn{2}{c}{ Lag period 3 } \\
\hline Null Hypothesis: & F-Statistic & Probability & F-Statistic & Probability \\
\hline VOL does not Granger Cause ISI & $0.39000^{*}$ & 0.67824 & 0.24716 & 0.86314 \\
ISI does not Granger Cause VOL & $2.88904^{*}$ & 0.06098 & $2.21124^{*}$ & 0.09277 \\
\hline
\end{tabular}

\section{Summary}

If Through the analysis, this paper finds that past market return is an important factor affecting investor sentiment in the short-term, while investor sentiment is an important factor in market volatility. These findings are important for investors and other stakeholders. In particular, during China's transition period, in the process of policy design, system construction, and related monitoring, the government should avoid making changes that could significantly change stock returns, thereby affecting investor sentiment, and finally leading to huge fluctuations in the stock market and exacerbating the stock market volatility. Unless effectively controlled, it will threaten the health and stability of financial markets, and ultimately affect the steady and rapid economic development.

\section{References}

[1] Baker M, Wurgler J, Yuan Y. Global, Local, and Contagious Investor Sentiment [Z]. AFA Atlanta Meetings Paper, 2010

[2] Thaler R. The End of Behavioral Finance [J]. Financial Analysts Journal, 1999, 55(6):12-17.

[3] Qiu L, Welch I. Investor sentiment measures [Z]. National Bureau of Economic Research, Working Paper No. 10794, Issued in September 2004

[4] Lee C, Shleifer A, Thaler R. Investor sentiment and the closed-end fund puzzle [J]. Journal of Finance, 1991, 46(1): 75-109

[5] Baker M, Stein J. Market liquidity as a sentiment indicator [J]. Journal of Financial Markets, 2004, 7(3):271-299 